\title{
The Culture of Martial Arts Performance: History, Current Situation and Prospect
}

\author{
Baozhan Wu \\ School of Physical Education \\ Neijiang Normal University \\ Neijiang , China
}

\begin{abstract}
Currently, the martial arts performance has changed in its cultural connotation and external representation, and with its value function diversified, it has become a "booster" of a country with martial arts to make domestic and foreign propaganda and a traditional culture item of people to make entertainment and appreciation. This paper applies the methods of literature, observation and logic analysis to make a review and prospect of martial art performance for its development, including the origin and evolution of martial art performance, the present state and value function of martial art performance, and the development trend under multicultural infiltration, so as to provide a theoretical basis for the healthy development of martial art performance culture.
\end{abstract}

Keywords-culture; martial arts performance; history; current situation; prospect

\section{INTRODUCTION}

Martial arts performance is a national traditional cultural activity that has martial arts as its performance materials and blends with a variety of artistic expression forms ${ }^{[1]}$, and under the influence of traditional Chinese culture, it produced, formed and matured, containing the true meaning of traditional culture in Confucianism, Buddhism, Taoism, dance and other categories, so it is regarded as the holographic carrier of traditional Chinese culture. With the changes in social history, martial arts performance has a constant innovation, evolution and development of its appellation, value and function. Its growth process is detailedly recorded in the historical literatures, known extensively in the world, such as the "Wu dance" in the ancient time to be used worship and practice military soldiers. It is recorded in the Zhou $\mathrm{Li} \cdot \mathrm{Di}$ Guan: "the dance for soldiers, is the Ganqi dance" ${ }^{[2]}$; it is recorded in the Jin Shu - Le Shang: "in the third year of Huangchu period, Bayu dance was changed into Zhaowu dance ... and in the Jin Dynasty, Zhaowu dance was also changed into Xuanwu dance" [3]; the Le Shu said: "Wen dance represents culture and Wu dance indicates military." such examples are too numerous to mention one by one. ${ }^{[4]}$ Additionally, the "martial arts drama" that is provided for entertainment and appreciation of modern people and for the wide dissemination of traditional Chinese culture, has often appeared in the academic monographs, periodicals, news newspapers and so on. It can be said that martial arts performances have made a constant evolvement

Fund project: the Research Project (14SB0157) of Sichuan Provincial Department of Education. and development from the early emerge to the present maturity, and its existence affects the training form of military soldiers, the continuity and spread of people's spiritual living standards and traditional culture. Martial arts performance is a traditional cultural activity of China for five thousand years, and also one of precious cultural heritages produced in China. we pay attention to the development countermeasures of martial arts, marketing operation and development, cultural transmission value and other issues, while its history, current situation and prospects are more worthy of our further exploration and research.

\section{WU DANCE: THE "FORMER" OF MARTIAL ARTS PERFORMANCE}

\section{A. Origin}

In order to achieve the designated witchcraft by dint of or by control of some kind of power beyond ordinary people, primitive people often use the symbolic form of song and dance to carry out certain ritual performances. Before the beginning of a war, people will carry out some ritual performances that are integrated with fighting action to pray for victory and practice the martial skills of soldiers. At this point, witchcraft will be upgraded into a large dance ${ }^{[5] 248}$, that is the original martial arts performance. The Huai Nan Hong Bie Jie - Miu Cheng Xun recorded that in the Shun period, Sanmiao made a rebellion, was defeated for three times but not convinced, so $\mathrm{Yu}$ would send armed forces to suppress it. "Perform Ganqi dance between two stages, and then Sanmiao is convinced" ${ }^{\prime[6]}$. The record of this historical event indicates the value and function of $\mathrm{Wu}$ dance in the military activities, which is the early written record of $\mathrm{Wu}$ dance used in the military. "Qianqi dance" can not only be used as a way to practice the military, but also show the military power to make enemy retreat without fight. Similarly, the Shan Hai Jing · Hai Wai Xi Jing described a mythology that "Xingtian wanted to contest with Tiandi for the supreme power of the spirit world, Tiandi cut off his head and buried in the Changyang Mountains, but Xingtian took his nipples as eyes and his bellybutton as mouth, waving the shield and broadax, to perform Ganqi dance for a war" ${ }^{\text {[7] }}$. This is not only an artistic summary of the reality of primitive social warfare, but also a reflection of the actual situation of $\mathrm{Wu}$ dance practice from a side. In ancient times $\mathrm{Wu}$ dance is not only used for military training and force display, but also expresses people's joy for a 
war victory and their desire for a good life in the ancient human. Such as the "large Wu dance" in the Western Zhou Dynasty, is created by the King Wu of Zhou to celebrate the success of destroying the King Zhou of Shang, and the whole dance consists of six sections to show the whole victory process of the King $\mathrm{Wu}$ destroying the King Zhou ${ }^{[8]}{ }^{82}$; for another example, the "Cangyuan rock paintings" found in Yunnan Province in 1965, which describes the vivid scene of Wu dance, reflects people's life and entertainment at that time.

\section{B. Evolution}

In the pre-Qin period, $\mathrm{Wu}$ dance was often used for sacrificial celebrations, military practices and force display. At the same time, it also had the recreational and educational functions. During this period, people divided $\mathrm{Wu}$ dance is into three categories: "Wan dance", "Xiang dance", "Great Wu dance". According to the historical records, "Wan dance" is the way of military training at that time; "Xiang dance" is the activity of appreciation and entertainment; and "Great $\mathrm{Wu}$ dance" is used to make celebration. After Qin unified the world, Wu dance was in a stagnant state, with little recorded in the "historical literatures", and till the Warring States period, the "dance" and "martial art" of "Wu dance" began to gradually divide, the Jiao-Di opera with "equal force between the two" got popular gradually.

In the Han Dynasty, the Jiao-Di opera got a rapid development, its content was increased year by year, the growing scale has exceeded the content scope of "Jiao-Di", and in the Eastern Han Dynasty, it renamed as "Acrobatics". At the time, there had been a variety of weapon dance, such as sword dance, broadsword dance and halbert dance. Xiang Zhuang playing sword in the well-known historical allusion "Banquet at Hongmen" is just a true portrayal of weapon dance. Before playing sword, Xiang Zhuang said "Your Majesty wants to drink with Pei Gong, but there is no thing to help the fun, let me play sword dance for you", by which we can see it has been already common to play sword dance for entertainment. ${ }^{[9]} 91$ After the Wei-Jin-Southern and Northern Dynasties, $\mathrm{Wu}$ dance widely absorbed and integrated dance, music, acrobatics and drama and other cultural elements on the base of succession of the pre-Qin Wu dance for royal court, to enrich its content and form. At the same time, this also promoted the new development of $\mathrm{Wu}$ dance, such as the "Great $\mathrm{Wu}$ dance", which is continued and carried out a number of innovation in content and form, and its name is also changed for several times, first "Great Wu dance" into "Bayu dance", and into "Zhao Wu dance" and then into "Xuanwu dance" in the Jin Dynasty.

In the Tang Dynasty, Wu dance had a new development, and especially the sword dance was prominent and became a social conduct at that time. Such as " take three cups of wine, hold sword to dance under the moonlight, the dance on the moon, loudly sigh with tears pouring off" (Chant of Jade Pot); "You will travel thousands of miles, brandish dagger to try the tiger's den. After drinking three cups of wine, pull out Longquan sword to dance till you are dizzy."(Send General Tao of the Imperial Guard Troops ${ }^{[10]}$. All these are vivid descriptions of sword dance by the great poet $\mathrm{Li}$ Bai. Additionally, the Watch Lady Gong Sun Playing Sword written by the poet $\mathrm{Du} \mathrm{Fu}$, famous through the ages, also provides a circumstantial evidence for sword dance popular in the Tang Dynasty. The foreign cultural exchanges were frequent in the prosperous Tang Dynasty, and with the introduction of heterogeneous culture, dance got a rapid development, especially $\mathrm{Wu}$ dance had reached the peak.

In the Song and Yuan Dynasties, Wu dance began to spread from the royal court to the countryside, the performance places for $\mathrm{Wu}$ dance and the open space for $\mathrm{Wu}$ dance are everywhere in cities and countryside. The professional $\mathrm{Wu}$ dance performers emerged who made a living by performance, known as the "LuQi people". The Meng Liang Lu, recording the artist performance in the city, said: "first several pairs of nuzhans (female wrestler) play Taozi to attract people to watch, then followed by the brawn contest", among which Taozi is a double-people practice for appreciation, called "boxing" at the time. ${ }^{[11]} 82$. From this, it can be seen that "martial arts" and "dance" of Wu dance has been separated from each other. Zaju (poetic drama set to music) is flourishing in the Yuan Dynasty, of which dramatic martial arts is another course of development of $\mathrm{Wu}$ dance.

During the Ming and Qing Dynasties, $\mathrm{Wu}$ dance is separated, then dance and martial arts are basically formed, and with the increasing military training and cultural and entertainment projects, "Wu dance" gradually began to fade out from people's attention; and with the rise of Cheng Zhu Neo-Confucianism, Wu dance finally faded out of the stage of history ${ }^{[12]}$. But we can vaguely peep the original appearance of $\mathrm{Wu}$ dance from the Zhong He Shao Music in the Ming Dynasty and the Qing Dynasty.

\section{Stage MARTIAL ARTS PERFORMANCES: TODAY'S MARTIAL ARTS PERFORMANCES}

\section{A. The Perfect Integration of Multiple Elements}

Martial arts performance is adjusted and innovated to adapt to the changes of social and ecological environment and the value function in the times, and integrated with more modern new elements, such as dance, music, lighting, multi-functional stage, multimedia background and other modern dance means. In consideration of the theme, plot content, character modeling and performance effect requirements of martial arts stage performance, and in order to reflect the stage atmosphere and highlight the artistic conception of martial arts performance as well as the unique appearance of each actor, the design of scene, lighting, makeup, dressing, props and others are added in the performance stage, so as to create a completely new visual effect of supplement and integration each other. The technical characteristics and style of martial arts is the core elements of action arrangement, based on which some exaggerated novel techniques are used in the artistic processing. The background music adopts the integrated ancient and modern national music. And more attention is paid to the reflection of cultural connotation in the story plot, to fully demonstrate the impressive charm and necessary functions of modern martial arts performances. Such as the stage martial arts performances Playing Chess, The Charm of Sword and Book, The Landscape Like A Picture on the Spring Festival Gala of 2010, 2014 and 2015, which have the multi- 
purpose stage, innovative action arrangement, alternating ancient and modern sweet notes and creative background, make us feel everything new and fresh and indulge in pleasure for a long time; in addition, the large original stage martial arts drama Shaolin in Wind, Bodhi in Wind, The Legend of Stick Monksand the Shaolin martial arts stage drama Space show the story at the stage with the background music, and under the reflection of stage lighting and stage set, they vividly interpreter the Chinese nation's culture of thousands of years.

\section{B. The Disseminators and Spreaders of Chinese Traditional Culture}

Since 1936, the Chinese martial arts delegation has gone to Berlin of Germany for performance, and then Chinese national martial arts team, national martial arts performance troupe, Beijing martial arts team, Shaolin monks group and other groups have successively been invited to visit abroad for cultural exchange, during which they present their wonderful performances such as a series of skills in Wushu, Free Boxing and Kung fu stage drama, bring foreigners with rich cultural feast, greatly spread Chinese martial arts culture everywhere in the world and opened a new window for Chinese and foreign cultural exchanges. Today, all the martial arts performance groups of China are carrying out domestic and foreign touring performances, their actions in the performance of skills in Wushu, Free Boxing and Kung fu stage drama are all full of traditional Chinese culture, making a large number of domestic and foreign martial arts enthusiasts engaged in the practice of martial arts and the knowledge and study of the culture related to martial arts. The people engaged in the practice of martial arts increase, which lays a solid foundation for carrying forward the techniques and culture of martial arts.

\section{The Function of Recreational Value}

The so-called recreation and entertainment is a way of life to pursue physical and mental pleasure, spiritual enrichment and quality life based on a certain guaranty of economy, material, time and social environment. ${ }^{[13]}$ The change of social environment makes the art value of attack and defence in wushu weaken increasingly and further promotes the popularity of martial arts performances. Today, people have no trouble in survival and their spiritual and emotional needs become clear ${ }^{[14]}$, so the recreational and recreational programs become very active, which help the appreciators cultivate their taste, release pressure and tiredness, pleasure their body and mind. In the large scale of cultural feast in the New Year's Eve Spring Festival, in the various scales of grand opening ceremonies and in the small scale of festival, market fair, temple fair and cultural activities, there often are martial arts performing groups and martial arts enthusiasts presenting performance, to bring fun, entertainment, learning and communication. ${ }^{[15]}$ Many a classic works that bring mental recreation, uplift the mind and the spirit and open the mind, have become the inevitable choice of the public for recreation and entertainment.

\section{MultiPle INFILTRATION: THE FUtURE OF MARTIAL ARTS PERFORMANCES}

With the change of time, the large scale of martial arts performance, taking martial arts elements as the core and blending with folk art, dance, acrobatics, science and technology and other multiple elements, is developing toward a diversified and comprehensive style ${ }^{[16]}$. The integration of multi-elements makes martial arts performance have a richer content and more profound cultural connotation, a deep visual impression and a stronger force of Chinese traditional culture promotion, so as to open a "window" for the cultural exchange, build a platform for the traditional culture display and set up a "lighthouse" for people's attention.

The integration of regional feature culture into martial arts produces a wide impact on the form, content and meaning expression of martial arts performance. In recent years, the large-scale martial arts performances are mostly based on the folk tales, stories, anecdotes in the creation place, showing a unique local customs and folk culture and making the whole program has more rich cultural atmosphere and local characteristics, so that the audience can have a fine experience and taste in the memory. In the future, this trend will continue. Geographically, China's vast territory is divided into seven regions, including North China, Northeast, East China, Central China, South China, Southwest and Northwest, of which each has a number of provinces, and each province has rich and profound traditional cultural resources, so martial arts performance has an inexhaustible material source.

The artistic use of martial arts performance stage is becoming more and more extensive. With the rapid development of society, science and technology gets a constant progress, which provides a technical support and guarantee for martial arts stage performances to become more colorful and pleasing. Such as the stage drama of Shaolin Kung Fu series has movable stage, special effects lighting, creative props, features costumes and pleasing sound in a interactive shine to provide a wonderful mood for martial arts performances, so that it attracts people, brings people into story to experience, and makes countless viewers convinced in vision and audition; and additionally, so do the martial arts performances in the annual Spring Festival Gala. With the continuous progress of science and technology, the artistic trend of stage will move forward so that martial arts performances reach a new artistic peak.

Martial arts performance has integrated modern dance, drama, acrobatics and other different forms of art, which will be a form of expression for the future, and the diversified theme and design and the varied forms of expression can bring richer and vivider content ${ }^{[17]}$. As the improvement of material level has promoted the increase of spiritual and cultural needs, people's aesthetic and appreciative standard has become higher. The simple and repeated, poor and stuffy form of expression will no longer attract people, and it will be abandoned and eliminated gradually, while the innovative and changeful, wonderful and comparable form of expression will attract people to appreciate it. To keep and develop martial arts performance, the integration of diversified art forms will be the inevitable choice in the future. 


\section{CONCLUSION}

Martial arts performance was provided for the productive and living necessity in the primitive society but now for the material and spiritual enjoyment in the social life, and for the war demand in the ancient time but now for recreation, cultural exchange and traditional culture promotion; provided only as the simple religious ritual in the past but now supported by stage technology; provided for the ancient single art reflection but now provided with diversified form of expression; provided with local characteristics but now with national traditional culture. In the whole history of martial arts performance for thousands of years, martial arts performance plays a different historical role in different historical periods, but also it contains a wealth of human wisdom. We should take the initiative to explore and develop the martial arts performance culture to make it grow rapidly, and further to promote the rapid development of other related fields to make them serve the community and the people.

\section{REFERENCES}

[1] Meng Tao. The influence of martial arts stage performance on the spread of Chinese martial arts in the United States [J]. Journal of Capital Institute of Physical Education, 2014 (4): 311-314.

[2] [Qing] Yong Rong, Ji Yun, et al. Si Ku Quan Shu (Wen Yuan Ge Ben) Volume 96 · Zhou Li Quan Jing Shi Yuan (V) [M]. Shanghai: Shanghai Ancient Books Publishing House, 1987,664.

[3] [Tang] Fang Xuanling, et al. Jin Book 3 . Volume 22 [M]. Beijing: Zhonghua Book Company, 1974,694.

[4] [Qing] Yong Rong, Ji Yun, et al. Si Ku Quan Shu (Wen Yuan Ge Ben) Volume211 . Music Book (54th) [M]. Shanghai: Shanghai Ancient Books Publishing House, 1987,257.

[5] Zhou Weiliang. Advanced Course of Introduction to National Traditional Sports [M]. Beijing: Higher Education Press, 2003.

[6] [Qing] Yong Rong, Ji Yun, et al. Si Ku Quan Shu (Wen Yuan Ge Ben) Volume 848 . Huai Nan Hong Bie Jie (10th) [M]. Shanghai: Shanghai Ancient Books Publishing House, 1987,613.

[7] [Jin] Guo Puzhu. Shanhai Scripture · Overseas Western Scripture [M]. Shanghai: Shanghai Ancient Books Publishing House, 2015,253.

[8] Same with [5]

[9] Same with [5]

[10] Ren Hai. Ancient Chinese Martial Arts [M]. Beijing: China International Broadcasting Publishing House, 2011,34.

[11] Same with [5]

[12] Li Cuixia, Zhao Min, Wei Biao. Historic Survey of Wushu Culture Changes [J]. Fighting. Wushu Science, 2006,8.

[13] Yang Bo. Study on the traceability and changes of Longshi Sports in Recreational Function [D]. Beijing: Beijing Sport University, 2002: 1011.

[14] Xie Miqing. The Sports' Recreational Function and The building of Harmonious Society $[\mathrm{J}]$. Journal of Wuhan Institute of Physical Education, 2007 (11): 7-11.

[15] Yu Jianping. Value: The Common Interests of Wushu Performance in Appreciation and Economy[J]. Fighting - Wushu Science, 2015 (6): 11 12.

[16] Zhao Futian, Li Lei, Wang Haiou. Analysis on the Development and Trend of Martial Arts Performance in the New Period [J]. Journal of Chinese Wushu Studies, 2012 (8-10): 99-103.

[17] Same with [17] 